\title{
Impulse control disorders in eating disorders: clinical and therapeutic implications
}

\author{
Fernando Fernández-Aranda ${ }^{a, b}$,* Susana Jiménez-Murcia ${ }^{a}$, Eva M. Álvarez-Moya ${ }^{a}$, \\ Roser Granero ${ }^{c}$, Julio Vallejo ${ }^{\mathrm{a}}$, Cynthia M. Bulik ${ }^{\mathrm{b}}$ \\ ${ }^{a}$ Department of Psychiatry, University Hospital of Bellvitge, 08907 Barcelona, Spain \\ ${ }^{\mathrm{b}}$ Departments of Psychiatry and Nutrition, University of North Carolina at Chapel Hill, Chapel Hill, NC 27599, USA \\ ${ }^{\mathrm{c}}$ Department of Psicobiologia i Metodología, Autonoma University of Barcelona, 08193 Barcelona, Spain
}

\begin{abstract}
Objective: Few studies have explored impulse control disorders (ICDs) in women with bulimia nervosa (BN). We explored the prevalence of lifetime ICDs in women with BN, compared the severity of eating disorder symptoms in women with BN with and without ICD, and compared their personality profiles to females with one form of ICD, namely, pathologic gambling.

Method: A total sample of 269 female patients consecutively admitted to our unit participated in the current study (173 BN without comorbid ICD [BN - ICD]; 54 BN with comorbid ICD [BN + ICD]; and 42 pathologic gamblers [PG]). All participants were diagnosed according to the Diagnostic and Statistical Manual of Mental Disorders, Fourth Edition, criteria.

Evaluation: Assessment measures included the Symptom Checklist-90 revised and the Temperament and Character Inventory-revised, as well as a number of other clinical and psychopathologic indices.

Results: In BN, the observed lifetime prevalence of ICD was $23.8 \%$. Lifetime compulsive buying (17.6\%) and intermittent explosive disorder $(13.2 \%)$ were the most frequently reported ICD. Bulimia nervosa subtype was not significantly associated with lifetime ICD $(P=$ $.051)$ or with ICD subtype $(P=.253)$. After using multinomial regression models, we observed that $\mathrm{BN}+\mathrm{ICD}$ and $\mathrm{PG}$ showed the highest scores on novelty seeking $(P<.0001)$. But BN + ICD women had the lowest scores on self-directedness $(P<.03)$ and higher scores on general psychopathology $(P<.01)$ and drug abuse $(P<.01)$.

Conclusions: Individuals with BN + lifetime ICD presented more extreme personality profiles, especially on novelty seeking and impulsivity, and general psychopathology than individuals with BN without ICD. On some personality traits, those BN + ICD more closely resembled individuals with $\mathrm{PG}$ than those with $\mathrm{BN}$ without ICD.

(C) 2006 Elsevier Inc. All rights reserved.
\end{abstract}

\section{Introduction}

Impulsivity is a trait common to several psychiatric disorders, including personality disorders (ie, borderline personality disorder) [1], psychoactive substance use disorders [2], eating disorders [3], pathologic gambling, and other impulse control disorders (ICD) [4]. The association between eating disorder and impulsivity has been documented widely in the literature $[5,6]$ - not only in bulimia nervosa $(\mathrm{BN})$, but also in the bingeing-purging subtype of anorexia nervosa [7]. In individuals with eating disorders, higher impulsivity has been associated with eating disorder subtype [8], severity of eating disorder symptoms [9], greater comorbidity [3], genetic factors [10], poorer psychologic functioning [11],

* Corresponding author. Tel.: +34 93 2607922; fax: +34 932607658.

E-mail address: ffernandez@csub.scs.es (F. Fernández-Aranda). altered biochemical functioning [12], less effective coping strategies [13], feelings of hunger [14], poor personality functioning [15], and poorer treatment outcome [16]. Moreover, high rates of impulsive behaviors have been described in individuals with eating disorders, including selfinjurious behavior [17], drug or alcohol abuse [3,18], stealing [19-21], and sexual promiscuity [7,22].

In the general population, impulsivity has been associated with involvement in problem behaviors during adolescence [23], drug use [24], gambling, alcohol use, and alcohol dependence [25], but also for developing an eating disorder $[26,27]$.

Although many studies of eating disorder have explored impulsivity as a behavior or as a personality trait, the relation between eating disorder and diagnosed ICDs, including intermittent explosive disorder (IED), kleptomania, 
pyromania, pathologic gambling, and trichotillomania, has rarely been investigated. In eating disorders, our information about ICD is limited to a few case studies on kleptomania [28,29] and trichotillomania [30], as well as isolated case series examining compulsive buying [31]. Giving the paucity of systematic investigations, few firm conclusions can be drawn regarding the nature of the relation between eating disorder and ICD. Even in the absence of compelling data, clinical formulations of eating disorders that focus on shared features with ICDs have informed treatment development [32-37].

The lifetime prevalence of ICD has been reported to be between $9 \%$ and $29 \%$ in individuals with affective disorders [38,39] and between $10 \%$ and $22 \%$ in individuals with obsessive-compulsive disorders [40,41]. The few studies that have reported ICDs in eating disorders report a lifetime prevalence of between $3 \%$ and $19 \%$ [19,42]. In general psychiatric populations, individuals who also present with ICD tend to report earlier age of onset and greater severity of the primary disorder, greater comorbidity, and poorer prognosis $[38,40]$.

\subsection{Aims of the study}

The goals of the present article were 3-fold: (1) to identify the prevalence of lifetime ICD in a clinical sample of individuals with $\mathrm{BN},(2)$ to analyze whether patients with $\mathrm{BN}$ with lifetime ICD exhibit more severe eating disorder symptoms and greater general psychopathology than patients with $\mathrm{BN}$ without ICD, and (3) to compare the personality profiles of females with $\mathrm{BN}$ only, BN + ICD, and individuals with pathologic gambling (a common form of ICD) who do not have history of an eating disorder.

\section{Material and methods}

\subsection{Participants}

A total sample of 269 female patients participated in the current study (173 BN without comorbid ICD [BN - ICD], $54 \mathrm{BN}$ with comorbid ICD [BN + ICD], and 42 pathologic gamblers [PG]). All participants were diagnosed according to the Diagnostic and Statistical Manual of Mental Disorders, Fourth Edition [43], criteria using a semistructured clinical interview conducted by experienced psychologists and psychiatrists. Participants were consecutive referrals for assessment and treatment at the Department of Psychiatry of the Bellvitge University Hospital in Barcelona, Spain. With regard to the diagnostic subtypes, $86.3 \%(\mathrm{n}=196)$ of the patients with $\mathrm{BN}$ were purging subtype, but this percentage did not differ across the $\mathrm{BN}+$ ICD and BN - ICD groups $\left(\chi_{1}^{2}=1.421, P>.05,87.9 \%\right.$ in $\mathrm{BN}-\mathrm{ICD}$ vs $81.5 \%$ in $\mathrm{BN}+\mathrm{ICD})$. Eighty-eight percent $(\mathrm{n}=37)$ of the patients with PG were slot machine gamblers and $12 \%(n=5)$ bingo players.

Sociodemographic and clinical characteristics of the 3 groups follow. For patients with BN - ICD ( $=173)$, the mean age was 25.7 years (SD, 6.9); the mean age of onset of their disorder was 19.4 years (SD, 6.5); and the mean duration of eating disorder was 6.4 years (SD, 4.8). They reported a weekly average of 7.3 binges $(\mathrm{SD}, 6.2)$ and 6.9 vomiting episodes (SD, 8.1), and their mean body mass index (BMI) was $24.2 \mathrm{~kg} / \mathrm{m}^{2}$ (SD, 4.6). Patients with BN + ICD $(n=54)$ were on average 26.7 years $(\mathrm{SD}, 6.7)$, reported the mean age of onset of their eating disorder of 18.9 years (SD, 6.2), and a reported a mean duration of illness of 7.9 years (SD, 6.3). They reported a weekly average of 7.9 (SD, 6.8) binges and 6.3 (SD, 8.1) vomiting episodes. Their mean BMI was $25.4 \mathrm{~kg} / \mathrm{m}^{2}$ (SD, 5.4). Finally, the mean age of the PG group $(\mathrm{n}=42)$ was 43.7 years (SD, 11.9); the mean age of onset of their disorder was 33.9 years (SD, 12.1); and mean duration of illness 8.8 years (SD, 8.2).

Individuals were excluded from the analyses if they had missing values for any diagnostic items. For the present analysis, from an initial sample of 526 eating disorder and 693 PG, the following individuals were excluded: $(a)$ males (34 eating disorder and $646 \mathrm{PG}$ ), (b) participants with an anorexia nervosa $(n=121)$ or eating disorder not otherwise specified $(\mathrm{n}=144),(c)$ patients with ICD who presented other lifetime ICD ( $\mathrm{n}=5$, compulsive buying). The entry into the study was between January 2003 and May 2005. The Ethics Committee of the Bellvitge University Hospital approved this study and informed consent was obtained from all participants.

\subsubsection{Assessment}

The patients completed the Temperament and Character Inventory-revised (TCI-R) [44] and the Symptom Checklist90 revised (SCL-90-R) [45]. Demographic-clinical information, including age, weight, height, and clinicalpsychopathologic variables, was also obtained. Additional demographic information, including education, occupation, and living arrangements, was obtained via semistructured interview.

\subsection{Evaluation of ICD and substance abuse/dependence}

Lifetime ICDs and alcohol and drug abuse/dependence were assessed with the Structured Clinical Interview for Diagnostic and Statistical Manual of Mental Disorders, Fourth Edition, axis I disorders [46].

\subsection{Symptom checklist-90 revised}

The SCL-90-R [45] is a widely used 90-item scale for assessing self-reported psychologic distress and psychopathology [47]. The test is usually scored on 9 primary symptom dimensions (comprising a total of 83 items): somatization, obsessive-compulsive, interpersonal sensitivity, depression, anxiety, hostility, phobic anxiety, paranoid ideation, and psychoticism. The global severity index, which is the participant's mean score (using all the 90 items), is a widely used global index of distress. This scale has been validated in Spanish population [48], obtaining a mean internal consistency of .75 (coefficient $\alpha$ ). 
Table 1

Lifetime prevalence of ICD not elsewhere classified from 227 patients with $\mathrm{BN}$

\begin{tabular}{lrcc}
\hline & $\mathrm{n}$ & Prevalence $(\%)$ & $95 \%$ CI $(\%)$ \\
\hline IED & 30 & 13.2 & $8.81-17.6$ \\
Kleptomania & 7 & 3.08 & $1.25-6.26$ \\
Pyromania & 0 & 0.00 & $0.00-1.61$ \\
Pathologic gambling & 2 & 0.88 & $0.10-3.14$ \\
Trichotillomania & 2 & 0.88 & $0.10-3.14$ \\
Compulsive buying & 40 & 17.6 & $12.7-22.6$ \\
\hline
\end{tabular}

\subsection{Temperament and character inventory-revised version}

The TCI-R [44] is a 240-item, 5-point Likert scale, reliable, and valid questionnaire that measures, as in the original TCI version [49], 7 dimensions of personality: 4 temperament (harm avoidance, novelty seeking, reward dependence, and persistence) and 3 character dimensions (self-directedness, cooperativeness, and self-transcendence). The performances of the Spanish version of the original questionnaire [50] and the revised version [51] have been well documented. The scales in the latter showed an internal consistency (coefficient $\alpha$ ) of .87.

\subsubsection{Procedure}

Experienced psychologists and psychiatrists completed the anamnesis during 2 structured face-to-face interviews. All assessors had undergone training for the Structured Clinical Interview for Diagnostic and Statistical Manual of Mental Disorders, Fourth Edition, interview, although interrater reliability was not calculated for this study. In addition to a comprehensive clinical and psychologic evaluation, additional demographic information was obtained.

\subsubsection{Statistical analysis}

The statistical analysis was conducted with SPSS, version 13 for Windows (SPSS, Chicago, Ill).

We first explored the prevalence of ICD across individuals with BN. Second, to determine whether the personality factors (measured by means of TCI-R) explained the factor group (BN + ICD vs BN - ICD vs PG), we used multinomial regression models. This procedure is a generalization of binary logistic regression for categorical responses, and its parameters are also interpreted as odds ratio $(\mathrm{OR})$ values. Because the TCI-R contains numerous subscales, we obtained different models: 1 global model that included the 7 total scales simultaneously and 7 additional models that represented each personality factor separately. The predictive capacity of each model was determined with the Nagelkerke's $R^{2}$ statistic. Third, for obtaining the association between the diagnoses and the actual psychopathologic state of patients, $S C L-90-R$ mean scores (adjusted by age) were compared with analysis of variance procedures and Bonferroni post hoc comparisons.

Finally, abuse of alcohol and drugs was compared across the 3 groups using logistic regression analysis. In all analyses, age was included as covariate. The adjustment level was analyzed by using the Hosmer and Lemeshow test.

\section{Results}

\subsection{Sociodemographic and clinical variables}

There were significant differences in age $(F=91.0, P=$ .0001 ), indicating that bulimic patients were younger than PGs. Age of onset of the primary disorder and duration of the primary disorder were also lower for patients with eating disorder $(F=48.8, P=.0001$, and $F=3.1, P=.05$, respectively).

Between the 2 bulimic groups (BN + ICD vs BN ICD), there were no significant differences on BMI $(F=$ $1.1, P=.345)$ or frequency of binges $(F=0.2, P=.831)$ or vomiting episodes $(F=0.1, P=.901)$.

\subsection{Prevalence of $I C D$ in individuals with $B N$}

The total BN sample considered in this study was 227 individuals. As shown in Table 1, the observed lifetime prevalence of ICD was $23.8 \%$ (95\% confidence interval [CI], 18.2\%-29.3\%). Lifetime compulsive buying and IED were the most frequently reported ICD. Bulimia nervosa subtype was not significantly associated with lifetime ICD $\left(\chi_{1}^{2}=3.8, P=.051\right)$ or with ICD subtype $\left(\chi_{4}^{2}=5.35, P=\right.$ .253 ); eating disorder subtype was therefore not used as a covariate in other analyses. Furthermore, $13.2 \%$ of women

Table 2

Predictive value of personality traits (measured with $T C I-R$ ) on the diagnosis

\begin{tabular}{|c|c|c|c|c|c|c|c|c|c|}
\hline \multirow[t]{2}{*}{ Total scores } & \multicolumn{3}{|c|}{$\underline{\mathrm{BN}}-\mathrm{ICD}$ vs $\mathrm{PG}$} & \multicolumn{3}{|c|}{$\underline{\mathrm{BN}}+\mathrm{ICD}$ vs $\mathrm{PG}$} & \multicolumn{3}{|c|}{$\underline{\mathrm{BN}}-\mathrm{ICD}$ vs $\mathrm{BN}+\mathrm{ICD}$} \\
\hline & $P$ & OR & $95 \% \mathrm{CI}$ & $P$ & OR & $95 \% \mathrm{CI}$ & $P$ & OR & $95 \% \mathrm{CI}$ \\
\hline Total novelty seeking ${ }^{\mathrm{a}}$ & $<.0005$ & 0.902 & $0.86-0.94$ & .006 & 0.937 & $0.90-0.98$ & .002 & 0.962 & 0.94-0.99 \\
\hline Total harm avoidance & .147 & 0.973 & $0.94-1.01$ & .160 & 0.973 & $0.94-1.01$ & .994 & 1.000 & $0.98-1.02$ \\
\hline Total reward dependence & .417 & 0.985 & $0.95-1.02$ & .361 & 0.982 & $0.95-1.02$ & .814 & 1.003 & $0.98-1.03$ \\
\hline Total persistence & .530 & 0.992 & $0.97-1.02$ & .663 & 0.994 & $0.97-1.02$ & .789 & 0.998 & $0.98-1.02$ \\
\hline Total self-directedness ${ }^{\mathrm{a}}$ & .169 & 0.970 & $0.93-1.01$ & .031 & 0.951 & 0.91-0.99 & .090 & 1.020 & $0.99-1.04$ \\
\hline Total cooperativeness & .821 & 1.004 & $0.97-1.04$ & .946 & 0.999 & $0.96-1.04$ & .607 & 1.005 & $0.99-1.03$ \\
\hline $\begin{array}{l}\text { Total self-transcendence } \\
R^{2}=0.506 \text { (Nagelkerke) }\end{array}$ & .948 & 1.000 & $0.96-1.04$ & .814 & 1.005 & $0.97-1.05$ & .615 & 0.994 & $0.97-1.02$ \\
\hline
\end{tabular}

Multinomial regression models adjusted by age.

a The score is predictive of the group. 
Table 3

Psychopathology (measured with $S C L-90-R$ ) related with the diagnosis

\begin{tabular}{|c|c|c|c|c|c|}
\hline \multirow[t]{2}{*}{ Subscale } & \multirow{2}{*}{$\frac{\mathrm{BN}-\mathrm{ICD}(\mathrm{n}=173)}{\operatorname{Mean}(\mathrm{SE})}$} & \multirow{2}{*}{$\frac{\mathrm{BN}+\mathrm{ICD}(\mathrm{n}=54)}{\text { Mean }(\mathrm{SE})}$} & \multirow{2}{*}{$\frac{\mathrm{PG}(\mathrm{n}=42)}{\text { Mean }(\mathrm{SE})}$} & \multirow[t]{2}{*}{$P$} & \multirow[t]{2}{*}{ Post hoc comparison $^{\mathrm{a}}(95 \% \mathrm{CI})$} \\
\hline & & & & & \\
\hline Somatization & $1.783(0.075)$ & $2.147(0.129)$ & $1.469(0.181)$ & .006 & $\begin{array}{l}\phi_{1}=-0.364(-0.718 \text { to }-0.010)^{\mathrm{b}} \\
\phi_{2}=0.313(-0.188 \text { to } 0.815) \\
\phi_{3}=0.677(0.124 \text { to } 1.231)^{\mathrm{b}}\end{array}$ \\
\hline Obsessive-compulsive & $1.987(0.067)$ & $2.379(0.115)$ & $1.567(0.161)$ & $<.0005$ & $\begin{array}{l}\phi_{1}=-0.392(-0.708 \text { to }-0.077)^{\mathrm{b}} \\
\phi_{2}=0.420(-0.027 \text { to } 0.867) \\
\phi_{3}=0.812(0.319 \text { to } 1.305)^{\mathrm{b}}\end{array}$ \\
\hline Interpersonal sensitivity & $2.144(0.070)$ & $2.352(0.120)$ & $1.468(0.169)$ & $<.0005$ & $\begin{array}{l}\phi_{1}=-0.207(-0.537 \text { to } 0.122) \\
\phi_{2}=0.676(0.210 \text { to } 1.143)^{\mathrm{b}} \\
\phi_{3}=0.884(0.369 \text { to } 1.399)^{\mathrm{b}}\end{array}$ \\
\hline Depression & $2.389(0.069)$ & $2.537(0.118)$ & $1.996(0.166)$ & .038 & $\begin{array}{l}\phi_{1}=-0.148(-0.473 \text { to } 0.176) \\
\phi_{2}=0.393(-0.067 \text { to } 0.852) \\
\phi_{3}=0.541(0.034 \text { to } 1.048)^{\mathrm{b}}\end{array}$ \\
\hline Anxiety & $1.860(0.072)$ & $2.146(0.124)$ & $1.454(0.174)$ & .007 & $\begin{array}{l}\phi_{1}=-0.286(-0.628 \text { to } 0.055) \\
\phi_{2}=0.406(-0.078 \text { to } 0.889) \\
\phi_{3}=0.692(0.159 \text { to } 1.225)^{\mathrm{b}}\end{array}$ \\
\hline Hostility & $1.467(0.075)$ & $1.829(0.129)$ & $1.421(0.181)$ & .039 & $\begin{array}{l}\phi_{1}=-0.362(-0.716 \text { to }-0.008)^{\mathrm{b}} \\
\phi_{2}=0.046(-0.456 \text { to } 0.548) \\
\phi_{3}=0.408(-0.145 \text { to } 0.962)\end{array}$ \\
\hline Phobic anxiety & $1.177(0.075)$ & $1.479(0.130)$ & $0.833(0.182)$ & .015 & $\begin{array}{l}\phi_{1}=-0.302(-0.658 \text { to } 0.054) \\
\phi_{2}=0.344(-0.161 \text { to } 0.848) \\
\phi_{3}=0.646(0.089 \text { to } 1.202)^{\mathrm{b}}\end{array}$ \\
\hline Paranoid ideation & $1.557(0.071)$ & $1.797(0.122)$ & $1.428(0.172)$ & .137 & $\begin{array}{l}\phi_{1}=-0.240(-0.576 \text { to } 0.096) \\
\phi_{2}=0.130(-0.346 \text { to } 0.605) \\
\phi_{3}=0.370(-0.155 \text { to } 0.894)\end{array}$ \\
\hline Psychoticism & $1.372(0.056)$ & $1.715(0.096)$ & $1.014(0.135)$ & $<.0005$ & $\begin{array}{l}\phi_{1}=-0.344(-0.607 \text { to }-0.080)^{\mathrm{b}} \\
\phi_{2}=0.358(-0.015 \text { to } 0.731) \\
\phi_{3}=0.701(0.290 \text { to } 1.113)^{\mathrm{b}}\end{array}$ \\
\hline Global severity index & $1.841(0.058)$ & $2.114(0.099)$ & $1.460(0.139)$ & .001 & $\begin{array}{l}\phi_{1}=-0.273(-0.544 \text { to }-0.001)^{\mathrm{b}} \\
\phi_{2}=0.381(-0.003 \text { to } 0.765) \\
\phi_{3}=0.654(0.230 \text { to } 1.078)^{\mathrm{b}}\end{array}$ \\
\hline Positive symptom total & $66.75(1.36)$ & $72.01(2.34)$ & $58.08(3.28)$ & .004 & $\begin{array}{l}\phi_{1}=-5.257(-11.68 \text { to } 1.167) \\
\phi_{2}=8.671(-0.424 \text { to } 17.77) \\
\phi_{3}=13.93(3.893 \text { to } 23.96)^{\mathrm{b}}\end{array}$ \\
\hline Positive symptom distress index & $2.38(0.044)$ & $2.563(0.076)$ & $2.194(0.107)$ & .016 & $\begin{array}{l}\phi_{1}=-0.187(-0.396 \text { to } 0.023) \\
\phi_{2}=0.183(-0.113 \text { to } 0.479) \\
\phi_{3}=0.370(0.043 \text { to } 0.697)^{\mathrm{b}}\end{array}$ \\
\hline
\end{tabular}

Analysis of variance adjusted for age.

$\phi_{1}=$ contrast for diagnoses $\mathrm{BN}-\mathrm{ICD}$ vs $\mathrm{BN}+\mathrm{ICD} ; \phi_{2}=$ contrast for diagnoses $\mathrm{BN}-\mathrm{ICD}$ vs $\mathrm{PG} ; \phi_{3}=$ contrast for a diagnoses $\mathrm{BN}+\mathrm{ICD}$ vs PG.

a Bonferroni procedure; means adjusted by age.

b The contrast is significant at .05 level.

with BN presented a single lifetime comorbid ICD $(95 \% \mathrm{CI}$, 8.81\%-17.6\%).

\subsection{Impulse control disorder and personality traits}

Comparing the TCI-R total subscale mean values across the 3 groups, statistically significant differences were obtained in novelty seeking (BN - ICD: 100.4 [SE, 1.2] vs BN + ICD: 110.0 [SE, 2.1] vs PG: 119.5 [SE, 2.9], $P<$ $.05)$ and self-directedness (BN - ICD: 113.9 [SE, 1.6] vs BN + ICD: 104.7 [SE, 2.7] vs PG: 113.5 [SE, 3.8]). When comparing these results with $T C I-R$ normative female Spanish values (described in reference [51]), the mean scores obtained on novelty seeking in all 3 groups were higher than the normal range (mean, 96.92; SD, 14.72), and the mean scores obtained on self-directedness were lower than the normal range values in females (mean, 149.85; SD, 18.35) (Table 2).
To assess the extent to which personality values were associated with group membership, we applied multinomial regression models. Results of a model that included the 7 total scores simultaneously indicated that high novelty seeking scores were more strongly associated with $\mathrm{PG}$ or $\mathrm{BN}+\mathrm{ICD}$ than with BN without ICD. Secondarily, when comparing $\mathrm{BN}+\mathrm{ICD}$ vs $\mathrm{PG}$, higher scores on selfdirectedness were more strongly associated with a diagnosis of PG.

The models that evaluated the TCI-R subscales independently indicated the following: First, comparing BN without ICD with $\mathrm{PG}$, we more strongly associated the diagnosis of PG with higher scores on impulsiveness-reflection, extravagance-reverse, social acceptance-intolerance, and self-conscience experience scales, and lower scores on dependence and perfectionism-pragmatism. Second, comparing $\mathrm{BN}+\mathrm{ICD}$ with $\mathrm{PG}$, we more strongly associated a PG 
diagnosis with higher scores on extravagance-reserve. Finally, comparing the $2 \mathrm{BN}$ groups, we associated the presence of ICD with higher scores on extravagancereserve, ambitious, and self-conscience experience, and lower scores on dependence.

\subsection{Impulse control disorder and psychopathology}

Comparing the mean current psychopathologic symptoms (measured by $S C L-90-R$ ) across the groups, we observed significant differences across groups on all scales except the paranoid subscale. As shown in Table 3, the patients of the $\mathrm{BN}+\mathrm{ICD}$ group reported the greatest psychopathology, with the individuals in the BN - ICD group reporting the lowest values.

\subsection{Impulse control disorder and current substances abuse}

Logistic regression models measuring the effect of group on alcohol and drug abuse revealed no significant differences across the groups on current alcohol abuse (the adjustment of the predictive models for alcohol abuse was 0.567, according to Hosmer and Lemeshow test). However, there were significant differences across the groups on current drug abuse, with patients with $\mathrm{BN}+$ ICD presenting with greater rates of drug abuse than patients with $\mathrm{BN}-$ ICD $(P=.012 ;$ OR $=1 / 0.400=2.5 ;$ CI 95\% OR, 1.2-5.1) (the adjustment of the predictive models for drug abuse was 0.429, according to Hosmer and Lemeshow test).

\section{Discussion}

We examined the lifetime prevalence of ICD in a clinical sample of individuals with $\mathrm{BN}$, addressed whether individuals with $\mathrm{BN}$ with ICD exhibit more severe eating disorder symptoms and greater general psychopathology than patients with $\mathrm{BN}$ without ICD, and compared personality profiles of females with $\mathrm{BN}$ with and without ICD to individuals with pathologic gambling (a form of ICD) who did not have eating disorders.

Confirming previous studies [31], we observed a modest but clinically significant lifetime prevalence of ICD among individuals with $\mathrm{BN}(23.8 \%)$. Extending previous investigations, the most frequently observed ICDs in this sample were compulsive buying (17.6\%) and IED (13.6\%). Furthermore, neither the presence of ICD nor the type of ICD differed across BN subtypes.

Regarding clinical variables, between the 2 groups of bulimia (BN + ICD vs BN - ICD), there were no significant differences on duration of the disorder, age of eating disorder onset, BMI, frequency of binges, or vomiting episodes. However, based on $S C L-90-R$ scores, individuals with $\mathrm{BN}+\mathrm{ICD}$ were more severely psychiatrically symptomatic than individuals in the other 2 groups. This could reflect the simple fact that these individuals by definition suffered from more than 1 disorder and therefore suffered under a greater burden of comorbidity.
With reference to the TCI-R scale of novelty seeking, individuals in all 3 groups scored above population norms. Moreover, across the 3 groups, a gradient was observed with the lowest scores in the individuals with BN without ICDs, followed by individuals with PG, and finally, those with $\mathrm{BN}+\mathrm{ICD}$.

In terms of the second TCI-R scale of interest, the lowest scores on self-directedness were observed in BN + ICD. The only statistically significant difference observed across groups was lower self-directedness in BN + ICD than in the PG groups. However, individuals in all 3 groups scored below population norms.

Drug use was more common in individuals with $\mathrm{BN}+$ ICD than BN - ICD, which, together with the temperament data, suggests that $\mathrm{BN}+\mathrm{ICD}$ may represent a subset of individuals with $\mathrm{BN}$ with greater overall impulsive tendencies. The concept of multiimpulsive bulimia has been previously introduced to the literature [5]. The extent to which the individuals observed here who have both $\mathrm{BN}$ and ICD map onto this previously identified subtype remains unclear.

Nonetheless, an impulsive subset of individuals with BN may have intriguing value for genetic and biologic studies of eating disorders. Genetically, the ongoing search for informative correlates and endophenotypes $[52,53]$ could benefit from further exploration of impulsivity markers for BN.

Limitations of this study include the relatively small sample size and the imperfect age matching with the PG group; the assessment procedures used did not allow us to evaluate either eating symptoms or impulsivity in depth; the absence of relevant measures (eg, onset of ICD and temporal relationship to the eating disorder) did not allow us to determine whether the BN or the ICD was primary in that group.

On the basis of prevalence data alone, ICDs, which are commonly omitted from the routine psychiatric evaluations, should be regularly assessed in individuals with $\mathrm{BN}$ because nearly one fourth of patients reported these disorders. Indeed, ICDs can be associated with severe financial (compulsive gambling) and interpersonal (IED) consequences that could interfere with the process of recovery from BN. In addition, impulsivity deserves further study as a potential informative covariate or endophenotype for genetic studies of $\mathrm{BN}$ as well as a potential symptom to target with both behavioral and pharmacologic interventions.

\section{Acknowledgments}

Financial support was received from Fondo de Investigación Sanitaria of Spain (FIS: G03-184; C03-06; PI-040619).

\section{References}

[1] Critchfield KL, Levy KN, Clarkin JF. The relationship between impulsivity, aggression, and impulsive-aggression in borderline 
personality disorder: an empirical analysis of self-report measures. J Personal Disord 2004;18(6):555 - 70.

[2] Bornovalova MA, Lejuez CW, Daughters SB, Zachary Rosenthal M, Lynch TR. Impulsivity as a common process across borderline personality and substance use disorders. Clin Psychol Rev 2005; 25(6):790-812.

[3] Bulik CM, Klump KL, Thornton L, Kaplan AS, Devlin B, Fichter $\mathrm{MM}$, et al. Alcohol use disorder comorbidity in eating disorders: a multicenter study. J Clin Psychiatry 2004;65(7):1000-6.

[4] Leyton M, Okazawa H, Diksic M, Paris J, Rosa P, Mzengeza S, et al Brain regional alpha- $\left[{ }^{11} \mathrm{C}\right]$ methyl-L-tryptophan trapping in impulsive subjects with borderline personality disorder. Am J Psychiatry 2001;158(5):775-82.

[5] Lacey JH, Evans CD. The impulsivist: a multi-impulsive personality disorder. Br J Addict 1986;81(5):641 - 9.

[6] Lacey JH. Self-damaging and addictive behaviour in bulimia nervosa. A catchment area study. Br J Psychiatry 1993;163:190-4.

[7] Matsunaga H, Kiriike N, Iwasaki Y, Miyata A, Matsui T, Nagata T, et al. Multi-impulsivity among bulimic patients in Japan. Int J Eat Disord 2000;27(3):348-52.

[8] Cassin SE, von Ranson KM. Personality and eating disorders: a decade in review. Clin Psychol Rev 2005;25(7):895-916.

[9] Newton JR, Freeman CP, Munro J. Impulsivity and dyscontrol in bulimia nervosa: is impulsivity an independent phenomenon or a marker of severity? Acta Psychiatr Scand 1993;87(6):389-94.

[10] Steiger H, Joober R, Israel M, Young SN, Ng Ying Kin NM, Gauvin L, et al. The 5HTTLPR polymorphism, psychopathologic symptoms, and platelet $[3 \mathrm{H}-]$ paroxetine binding in bulimic syndromes. Int J Eat Disord 2005;37(1):57-60.

[11] Duncan AE, Neuman RJ, Kramer J, Kuperman S, Hesselbrock V, Reich T, et al. Are there subgroups of bulimia nervosa based on comorbid psychiatric disorders? Int J Eat Disord 2005;37(1):19-25.

[12] Steiger H, Young SN, Kin NM, Koerner N, Israel M, Lageix P, et al. Implications of impulsive and affective symptoms for serotonin function in bulimia nervosa. Psychol Med 2001;31(1):85-95.

[13] Nagata T, Kawarada Y, Kiriike N, Iketani T. Multi-impulsivity of Japanese patients with eating disorders: primary and secondary impulsivity. Psychiatry Res 2000;94(3):239-50.

[14] Lyke JA, Spinella M. Associations among aspects of impulsivity and eating factors in a nonclinical sample. Int J Eat Disord 2004;36(2): 229-33.

[15] Wonderlich SA, Crosby RD, Joiner T, Peterson CB, Bardone-Cone A, Klein M, et al. Personality subtyping and bulimia nervosa: psychopathological and genetic correlates. Psychol Med 2005;35(5):649-57.

[16] Sohlberg S, Norring C, Holmgren S, Rosmark B. Impulsivity and long-term prognosis of psychiatric patients with anorexia nervosa/ bulimia nervosa. J Nerv Ment Dis 1989;177(5):249-58.

[17] Solano R, Aitken A, López C, Vallejo J, Fernández-Aranda F. Selfinjurious behaviour in eating disorders. Eur Eat Disord Rev 2005;13: $3-10$.

[18] García-Vilches I, Badía-Casanovas A, Fernández-Aranda F, JiménezMurcia S, Turón-Gil V, Vallejo-Ruiloba J. Characteristics of bulimic patients whose parents do or do not abuse alcohol. Eat Weight Disord 2002;7(3):232-8.

[19] Grant JE, Kim SW. Clinical characteristics and associated psychopathology of 22 patients with kleptomania. Compr Psychiatry 2002; 43(5):378 - 84.

[20] Vandereycken W, van Houdenhove VD. Stealing behavior in eating disorders: characteristics and associated psychopathology. Compr Psychiatry 1996;37(5):316-21.

[21] Mitchell JE, Fletcher L, Gibeau L, Pyle RL, Eckert E. Shoplifting in bulimia nervosa. Compr Psychiatry 1992;33(5):342-5.

[22] Wiederman MW, Pryor T. Multi-impulsivity among women with bulimia nervosa. Int J Eat Disord 1996;20(4):359-65.

[23] Cooper ML, Wood PK, Orcutt HK, Albino A. Personality and the predisposition to engage in risky or problem behaviors during adolescence. J Pers Soc Psychol 2003;84(2):390-410.
[24] Simons JS, Carey KB. Risk and vulnerability for marijuana use problems: the role of affect dysregulation. Psychol Addict Behav 2002;16(1):72-5.

[25] Poikolainen K. Risk factors for alcohol dependence: a case-control study. Alcohol Alcohol 2000;35(2):190-6.

[26] Stice E, Presnell K, Spangler D. Risk factors for binge eating onset in adolescent girls: a 2-year prospective investigation. Health Psychol 2002;21(2):131-8.

[27] Wonderlich SA, Connolly KM, Stice E. Impulsivity as a risk factor for eating disorder behavior: assessment implications with adolescents. Int J Eat Disord 2004;36(2):172-82.

[28] Leygraf N, Windgassen K. Pathological stealing exemplified by anorexia nervosa. Nervenarzt 1990;61(7):413-7.

[29] Bayle FJ, Chignon JM, Ades J, Loo H. Alternating addictions: apropos of 3 cases. Encephale 1996;22(4):293 - 7.

[30] Hall JR, McGill JC. Hypnobehavioral treatment of self-destructive behavior: trichotillomania and bulimia in the same patient. Am J Clin Hypn 1986;29(1):39-46.

[31] Mitchell JE, Redlin J, Wonderlich S, Crosby R, Faber R, Miltenberger $\mathrm{R}$, et al. The relationship between compulsive buying and eating disorders. Int J Eat Disord 2002;32(1):107-11.

[32] Shapira NA, Goldsmith TD, McElroy SL. Treatment of binge-eating disorder with topiramate: a clinical case series. J Clin Psychiatry 2000;61(5):368-672.

[33] Appolinario JC, McElroy SL. Pharmacological approaches in the treatment of binge eating disorder. Curr Drug Targets 2004;5(3):301 - 7 .

[34] Barbee JG. Topiramate in the treatment of severe bulimia nervosa with comorbid mood disorders: a case series. Int J Eat Disord 2003;33(4): $468-742$.

[35] Hedges DW, Reimherr FW, Hoopes SP, Rosenthal NR, Kamin M, Karim R, et al. Treatment of bulimia nervosa with topiramate in a randomized, double-blind, placebo-controlled trial, Part 2: improvement in psychiatric measures. J Clin Psychiatry 2003;64(12): 1449-54.

[36] Hoopes SP, Reimherr FW, Hedges DW, Rosenthal NR, Kamin M, Karim R, et al. Treatment of bulimia nervosa with topiramate in a randomized, double-blind, placebo-controlled trial, Part 1: improvement in binge and purge measures. J Clin Psychiatry 2003;64(11): $1335-41$.

[37] McElroy SL, Shapira NA, Arnold LM, Keck PE, Rosenthal NR, Wu $\mathrm{SC}$, et al. Topiramate in the long-term treatment of binge-eating disorder associated with obesity. J Clin Psychiatry 2004;65(11):1463-9.

[38] Lejoyeux M, Arbaretaz M, McLoughlin M, Ades J. Impulse control disorders and depression. J Nerv Ment Dis 2002;190(5):310-4.

[39] Zimmerman M, Chelminski I, McDermut W. Major depressive disorder and axis I diagnostic comorbidity. J Clin Psychiatry 2002; 63(3):187-93.

[40] Fontenelle LF, Mendlowicz MV, Versiani M. Impulse control disorders in patients with obsessive-compulsive disorder. Psychiatry Clin Neurosci 2005;59(1):30-7.

[41] Bienvenu OJ, Samuels JF, Riddle MA, Hoehn-Saric R, Liang KY, Cullen BA, et al. The relationship of obsessive-compulsive disorder to possible spectrum disorders: results from a family study. Biol Psychiatry 2000;48(4):287-93.

[42] McElroy SL. Recognition and treatment of DSM-IV intermittent explosive disorder. J Clin Psychiatry 1999;60(Suppl 15):12-6.

[43] APA. Diagnostic and statistical manual of mental disorders. Washington, DC: American Psychiatric Press; 1994.

[44] Cloninger CR. The temperament and character inventory-revised. St Louis (Mo): Center for Psychobiology of Personality, Washington University; 1999.

[45] Derogatis LR, Melisaratos N. The brief symptom inventory: an introductory report. Psychol Med 1983;13(3):595-605.

[46] First M, Gibbon M, Spitzer R, Williams J. Users guide for the structured clinical interview for DSM IV Axis I disorders-research version (SCID-I, version 2.0). New York: New York State Psychiatric Institute; 1996. 
[47] Derogatis L. SCL-90-R. A bibliography of research reports 19751990. Baltimore (Md): Clinical Psychometric Research; 1990.

[48] Derogatis L. SCL-90-R. Cuestionario de 90 síntomas-Manual. Madrid: TEA Editorial; 2002.

[49] Cloninger CR, Svrakic DM, Przybeck TR. A psychobiological model of temperament and character. Arch Gen Psychiatry 1993; 5(12):975 - 90.

[50] Gutierrez F, Torrens M, Boget T, Martin-Santos R, Sangorrin J, Perez $\mathrm{G}$, et al. Psychometric properties of the Temperament and Character Inventory (TCI) questionnaire in a Spanish psychiatric population. Acta Psychiatr Scand 2001;103(2):143-7.
[51] Gutiérrez-Zotes J, Bayón C, Montserrat C, Valero J, Labad A, Cloninger $\mathrm{R}$, et al. Inventario del Temperamento y el CarácterRevisado (TCI-R). Baremación y datos normativos en una muestra de población general. Actas Esp Psiquiatr 2004;32(1):8-15.

[52] Bulik CM, Bacanu SA, Klump KL, Fichter MM, Halmi KA, Keel P, et al. Selection of eating-disorder phenotypes for linkage analysis. Am J Med Genet B Neuropsychiatr Genet 2005;139:81 - 7 .

[53] Bacanu SA, Bulik CM, Klump KL, Fichter MM, Halmi KA, Keel P, et al. Linkage analysis of anorexia and bulimia nervosa cohorts using selected behavioral phenotypes as quantitative traits or covariates. Am J Med Genet B Neuropsychiatr Genet 2005;139:61 - 8 . 